\title{
ENSINO DE FÍSICA E EDUCAÇÃO INCLUSIVA: O ENSINO DA PRIMEIRA LEI DE NEWTON ${ }^{1}$
}

\author{
Sabrina Gomes COZENDEY ${ }^{2}$ \\ Maria da Piedade Resende da COSTA ${ }^{3}$ \\ Márlon Caetano Ramos PESSANHA ${ }^{4}$
}

RESUMO: Neste trabalho é apresentada uma discussão sobre a inclusão de alunos surdos na aula de Física. Busca-se discutir como construir um plano de aula para o ensino de primeira lei de Newton em um ambiente inclusivo de ensino. Utilizando uma proposta de ensino bilíngue é desenvolvido um plano de aula que conta um vídeo bilíngue, situações problemas para introduzir as discussões e um questionário fechado para avaliar a aprendizagem. Participaram da pesquisa dezoito alunos do segundo ano do ensino médio de uma escola estadual do interior do estado de São Paulo. Os resultados mostram que foi desenvolvida uma proposta inclusiva, uma vez que esta conseguiu assegurar a possibilidade de aprendizado a alunos com e sem deficiência auditiva, ao respeitar os ritmos e estilos de aprendizagem foi criada uma proposta que conseguiu ensinar a todos os alunos o mesmo conceito, ao mesmo tempo.

PALAVRAS-CHAVE: Educação inclusiva. Ensino de física. Surdez. Ensino bilíngue.

\section{Introdução}

A inclusão de pessoas com deficiência nas classes regulares, que hoje é tema de várias discussões, é fruto de uma longa jornada de lutas pelo direito a um ensino adequado.

Inicialmente o ensino de pessoas com deficiência ocorreu paralelamente ao ensino regular, em escolas especiais. Segundo Mendes (2006, p.388), “[...] a educação especial foi constituindo-se como um sistema paralelo ao sistema educacional geral, até que, por motivos morais, lógicos, científicos, políticos, econômicos e legais, surgiram as bases para uma proposta de unificação".

Os movimentos sociais pelos direitos humanos, intensificados basicamente na década de 1960, conscientizaram e sensibilizaram a sociedade sobre os prejuízos da segregação e da marginalização de indivíduos de grupos com status minoritários, tornando a segregação

\footnotetext{
${ }^{1} \mathrm{O}$ presente trabalho foi realizado com apoio do PROESP/CAPES, entidade do Governo Brasileiro voltada para a formação de recursos humanos.

${ }^{2}$ Pesquisadora Associada da UFSCar. UFSCar - Universidade Federal de São Carlos; Doutora em Educação Especial. UFSCar - Universidade Federal de São Carlos. Area de Concentração Educação do Indivíduo Especial. São Carlos- SP - Brasil. 13565-905- sgcfisica@yahoo.com.br

${ }^{3}$ UFSCar - Universidade Federal de São Carlos; Pesquisadora do departamento de Psicologia e Professora na Pós-graduação em Educação Especial. UFSCar - Universidade Federal de São Carlos. Area de Concentração Educação do Indivíduo Especial. São Carlos - SP - Brasil. 13565-905- piedade@ ufscar.br

${ }^{4}$ Doutorando em Ensino de Ciências. USP - Universidade de São Paulo. Area de Concentração. São Paulo - SP

- Brasil. 05508-040 - marlonpessanha@yahoo.com.br.
} 
sistemática de qualquer grupo ou criança uma prática intolerável. Tal contexto alicerçou uma espécie de base moral para a proposta de integração escolar, sob o argumento irrefutável de que todas as crianças com deficiências teriam o direito inalienável de participar de todos os programas e atividades cotidianas que eram acessíveis para as demais crianças (MENDES, 2006).

Segundo Mendes (2006) os motivos lógicos que foram base para a unificação da escola regular e da escola especial referem-se aos benefícios que surgiriam deste convívio. Os benefícios para os alunos com deficiência seriam:

[...] participar de ambientes de aprendizagem mais desafiadores; ter mais oportunidades para observar e aprender com alunos mais competentes; viver em contextos mais normalizantes e realistas para promover aprendizagens significativas; e ambientes sociais mais facilitadores e responsivos. Benefícios potenciais para os colegas sem deficiências seriam: a possibilidade de ensiná-los a aceitar as diferenças nas formas como as pessoas nascem, crescem e se desenvolvem, e promover neles atitudes de aceitação das próprias potencialidades e limitações. (MENDES, 2006, p.388).

Os motivos científicos que foram base para a proposta de unificação estão relacionadas a pesquisas que mostram o potencial de aprendizagem das pessoas com deficiência (MENDES, 2006).

Em relação ao fator político, este teve forte influência “[...] no movimento pela integração, ações políticas de diferentes grupos organizados, de portadores de deficiências, pais e profissionais, que passaram a exercer forte pressão no intuito de garantir os direitos fundamentais e evitar discriminações”. (MENDES, 2006, p.388).

Um outro fator crucial para a mudança nas práticas educacionais especiais ocorreu nas décadas de 1960 e 1970, onde foi constado um custo elevado para manter os programas de educação especial. Segundo Mendes (2006, p.388):

[...] até então, apenas os países considerados desenvolvidos haviam criado um sistema educacional paralelo para os portadores de deficiências. A partir da década de 1960, passou a ser também conveniente adotar a ideologia da integração pela economia que elas representariam para os cofres públicos.

Por fim, desde 1988 os documentos legais instituem a obrigatoriedade do poder publico quanto à oferta de oportunidades educacionais às pessoas com deficiência (MENDES, 2006). 
Desta forma, neste momento social, do século XX, é concebível que alunos com e sem deficiência estudem na mesma escola e na mesma turma. Por diferentes motivos, uma proposta de educação unificada é defendida e entendida como um meio para o crescimento mútuo de pessoas com e sem deficiência.

Em 1994, com a declaração das Nações Unidas sobre os princípios, políticas e práticas na área das necessidades educativas especiais surge uma grande força política para a construção de escolas inclusivas. Neste momento a educação unificada (ensino regular + ensino especial) passa ser entendida como educação inclusiva.

A educação inclusiva é mais um paradigma da educação, que pressupõe uma escola mais inclusiva, capaz de ensinar as pessoas que apresentam necessidades educacionais especiais e aquelas que não apresentam tal necessidade. Além disso, a educação inclusiva pressupõe que a escola será capaz de ensinar pessoas de diferentes culturas e raças, não somente pessoas com alguma deficiência. A inclusão escolar é vista muitas vezes como a inclusão de pessoas com deficiência na escola regular, contudo, a proposta de inclusão é muito maior, e está relacionada à capacidade da escola em ensinar pessoas que tem culturas e raças diferentes como é o caso dos indígenas e dos ciganos.

A escola inclusiva é fruto de uma grande discussão, que já dura algumas décadas. Assim, a proposta de inclusão de pessoas com deficiência na escola regular tem sido assumida como um direito fundamental em muitos documentos nacionais e internacionais; sendo alguns dos mais recentes: A Constituição Federal de 1988 (BRASIL, 1988), a Declaração Mundial sobre Educação para Todos (UNESCO, 1990), a Declaração de Salamanca (UNESCO, 1994), a Lei de Diretrizes e Bases da Educação Nacional, lei de Darcy Ribeiro, nº 9394 de 1996 (LDBEN 9.394/96) (BRASIL, 1996), a Convenção da Guatemala (1999), ratificada pelo Decreto no 3.956 (BRASIL, 2001), a Convenção dos Direitos das Pessoas com Deficiência (2007), ratificada e incorporada à constituição como Decreto Legislativo $n^{\circ}$ 186/2008 (BRASIL, 2008), a Política Nacional de Educação Especial na Perspectiva da Educação Inclusiva (BRASIL, 2007), entre outros dispositivos legais.

As mudanças feitas na LDBEN em 2013 ratificam a necessidade de se pensar um ensino adequado à inclusão de pessoas com deficiência nas turmas regulares, na lei consta que o “"...] atendimento educacional especializado gratuito aos educandos com deficiência, transtornos globais do desenvolvimento e altas habilidades ou superdotação, transversal a todos os níveis, etapas e modalidades, preferencialmente na rede regular de ensino". (BRASIL, 1996, p.2). 
Segundo a Política Nacional de Educação Especial na Perspectiva da Educação Inclusiva:

O movimento mundial pela educação inclusiva é uma ação política, cultural, social e pedagógica, desencadeada em defesa do direito de todos os alunos de estarem juntos, aprendendo e participando, sem nenhum tipo de discriminação. A educação inclusiva constitui um paradigma educacional fundamentado na concepção de direitos humanos, que conjuga igualdade e diferença como valores indissociáveis, e que avança em relação à ideia de equidade formal ao contextualizar as circunstâncias históricas da produção da exclusão dentro e fora da escola. (BRASIL, 2007, p.5).

A existência de escolas inclusivas pode ser considerada como um avanço na Educação Nacional, contudo, esta realidade não é positiva se as escolas não funcionarem como centros adequados de inclusão. E dizer que um sistema educacional inclusivo funciona é dizer que ele é capaz de oferecer oportunidades iguais a indivíduos com deficiência e sem deficiência em alcançar uma aprendizagem adequada a cada série.

Segundo Rodrigues (2006, p.302):

[...] o conceito de inclusão no âmbito especifico da educação implica inicialmente em rejeitar a exclusão (presencial ou acadêmica) de qualquer aluno da comunidade escolar. Para isso, a escola que pretende seguir uma política de educação inclusiva deve desenvolver práticas que valorizem a participação de cada aluno.

Neste sentido, a educação inclusiva "[...] pressupõe uma participação plena numa estrutura em que valores e práticas são delineados tendo em conta as características, interesses, objetivos e direitos de todos os participantes no ato educativo". (RODRIGUES, 2006, p.303).

Dentre os alunos com necessidades educacionais especiais que estão sendo matriculados nas escolas regulares estão os alunos com surdez. $\mathrm{O}$ aluno com surdez apresenta uma perda auditiva que muitas vezes o impedi de se comunicar por meio da língua oral. Contudo, mesmo privado da audição e assim, apresentando dificuldades para se comunicar, uma pessoa surda pode compreender uma mensagem, seja ela verbal ou não, visualmente a partir de alguns meios, a destacar-se: percepção dos gestos mímicos ou linguísticos (língua de sinais) e por meio da leitura labial ou orofacial.

Considerando o aspecto cultural da pessoa com surdez, que está relacionada à capacidade de ler o mundo por vias visuais, a escolarização do mesmo deve-se observar essa característica única de seu grupo (PERLIN; STROBEL, 2006). Sendo assim, não se pode 
dizer que os processos de ensino e de aprendizagem do aluno com surdez ocorrem da mesma forma que do aluno sem deficiência (SACKS, 1998).

Um dos aspectos que caracteriza a singularidade no processo educacional dos surdos é o fato de os mesmos necessitarem de uma proposta diferenciada de trabalho, por meio da oferta de uma educação bilíngue, isto é, uma proposta que pressuponha a utilização de duas línguas em sua escolarização: a Libras e a língua portuguesa.

Entende-se como Língua Brasileira de Sinais - Libras - a forma de comunicação e expressão, em que o sistema lingüístico de natureza visual-motora, com estrutura gramatical própria, constitui um sistema lingüístico de transmissão de idéias e fatos, oriundos de comunidades de pessoas surdas do Brasil (BRASIL, 2002).

Algumas mudanças têm ocorrido na legislação brasileira no sentido de valorizar e promover o uso Língua Brasileira de Sinais (Libras) como um meio de comunicação na educação regular. Em 2002, por meio da Lei 10.436/02, a Libras foi reconhecida como meio legal de comunicação e expressão das pessoas surdas (BRASIL, 2002).

Com o reconhecimento oficial da Libras e a regulamentação da inclusão, o aluno com deficiência auditiva adquiriu o direito de estudar em escolas regulares e ter auxílio de interpretes em sua educação, sendo esta de caráter bilíngue. O estudante com deficiência auditiva adquiriu também o direito de frequentar salas de recursos, que seriam os lugares adequados a aprender os conceitos não compreendidos na sala regular.

\section{Objetivo}

Desenvolver um plano de trabalho para ensinar o conceito de Primeira lei de Newton em uma turma inclusiva de Física que tenha incluído um aluno surdo.

\section{Método de Pesquisa}

Esta pesquisa consiste em um estudo de caso. Foi desenvolvida em uma escola estadual de nível médio localizada no interior de São Paulo. Participaram da pesquisa dezoito alunos do segundo ano do ensino médio, uma das alunas da turma tinha uma perda auditiva severa.

Nesta pesquisa buscou-se primeiramente conhecer a turma que participaria da pesquisa, para assim poder propor uma prática de ensino mais adequada à realidade destes alunos. 
Em seguida foi organizado um plano de trabalho para ensinar o conceito de Primeira lei de Newton.

Também foi desenvolvido um questionário com três questões problemas para ser utilizado em dois momentos na aula, um antes do desenvolvimento do plano de trabalho e outro após a realização da aula planejada.

\section{Plano de Trabalho}

Considerando a realidade da turma (inclusiva, com uma aluna surda) buscou-se desenvolver uma proposta de ensino bilíngue, que utilizasse o português e a Libras ao mesmo tempo.

Considerando a necessidade de trabalhar com um recurso lúdico que chamasse a atenção dos alunos, motivasse a participação, e favorece a aprendizagem de todos os alunos, optou-se por criar um vídeo educativo bilíngue. Um vídeo bilíngue é aquele que além de valorizar as imagens e as discussões em português utiliza a Libras.

Assim, foi desenvolvido um roteiro de vídeo com os pontos que deveriam ser abordados no vídeo: texto a ser narrado em português, texto a ser legendado em português, texto a ser apresentado em Libras, e, imagens a serem apresentadas no vídeo.

No quadro 1 é apresentado o roteiro desenvolvido para ensinar o conceito de Primeira lei de Newton.

\section{Quadro 1- Roteiro do vídeo sobre Primeira Lei de Newton}

\begin{tabular}{|c|c|c|}
\hline Cena 1 & Aspectos da cena & Fala /Narração /Legenda \\
\hline $\begin{array}{l}\text { Apresentação do } \\
\text { conceito de inércia } \\
\text { (primeira lei de } \\
\text { Newton). }\end{array}$ & $\begin{array}{l}\text { Usando roupa preta em um } \\
\text { estúdio improvisado, de fundo } \\
\text { claro, o intérprete grava os } \\
\text { correspondentes das falas em } \\
\text { Libras. }\end{array}$ & $\begin{array}{l}\text { - Hoje falaremos sobre a primeira lei } \\
\text { de Newton. } \\
\text { - A primeira lei de newton ou lei de } \\
\text { Inércia diz que: um corpo em repouso } \\
\text { continua em repouso [...] }\end{array}$ \\
\hline Cena 2 & Aspectos da cena & Animação 1 \\
\hline $\begin{array}{l}\text { Animação: } \\
\text { representando um } \\
\text { corpo em repouso. }\end{array}$ & $\begin{array}{l}\text { Em uma estrada um cachorro } \\
\text { encontra-se sobre um skate. A } \\
\text { língua do cachorro se mexe, } \\
\text { mostrando que este permanece } \\
\text { parado em cima do skate. }\end{array}$ & $\begin{array}{l}\text { Mostra que s } \\
\text { atuando sobr } \\
\text { este permane }\end{array}$ \\
\hline Cena 3 & Aspectos da cena & Fala /Narração /Legenda \\
\hline $\begin{array}{l}\text { Continuação } \\
\text { definicão }\end{array}$ & $\begin{array}{l}\text { Usando roupa preta em um } \\
\text { estúdio improvisado, de fundo }\end{array}$ & $\begin{array}{l}\text { - [...] Mas se exercida uma força } \\
\text { sobre o corpo, este pode entrar em }\end{array}$ \\
\hline
\end{tabular}


primeira lei de claro, o intérprete grava os movimento.

Newton. $\quad$ correspondentes das falas em

\begin{tabular}{|l|l|l|}
\hline & Libras. & \\
\hline Cena 4 & Aspectos da cena & Animação 2 \\
\hline Animação: & Em uma estrada uma pessoa & Mostra que
\end{tabular}

Animação: representando um empurra o skate no qual o resultante é aplicada sobre o corpo

Em uma estrada uma pessoa Mostra que quando uma força corpo saindo do cachorro estava em cima. $\mathrm{O}$ em repouso, este pode sair do \begin{tabular}{l|l} 
repouso. & skate sai do repouso e entra em repouso e se movimentar.
\end{tabular}

\begin{tabular}{|c|c|c|}
\hline & movimento. & \\
\hline Cena 5 & Aspectos da cena & Fala /Narração /Legenda \\
\hline $\begin{array}{|lll|}\text { Continuação } & \text { da } \\
\text { definição } & & \text { da } \\
\text { primeira } & \text { lei } & \text { de } \\
\text { Newton. } & & \\
\end{array}$ & $\begin{array}{l}\text { Usando roupa preta em um } \\
\text { estúdio improvisado, de fundo } \\
\text { claro, o intérprete grava os } \\
\text { correspondentes das falas em } \\
\text { Libras. }\end{array}$ & $\begin{array}{l}-[\ldots] \text { Um corpo em movimento } \\
\text { permanece em movimento. }\end{array}$ \\
\hline Cena 6 & Aspectos da cena & Animação 3 \\
\hline $\begin{array}{|ll|}\text { Animação: } & \\
\text { apresentação de } & \text { um } \\
\text { corpo } & \text { em } \\
\text { movimento. } & \\
\end{array}$ & $\begin{array}{l}\text { Em uma estrada, sem atrito, um } \\
\text { skate com um cachorro em cima } \\
\text { permanece em movimento. }\end{array}$ & $\begin{array}{l}\text { Mostra que quando não há força } \\
\text { resultante atuando sobre um corpo } \\
\text { em movimento, este permanece em } \\
\text { movimento. }\end{array}$ \\
\hline Cena 7 & Aspectos da cena & Fala /Narração /Legenda \\
\hline \begin{tabular}{|lll} 
Continuação & da \\
definição & & da \\
primeira & lei & de \\
Newton. & &
\end{tabular} & $\begin{array}{l}\text { Usando roupa preta em um } \\
\text { estúdio improvisado, de fundo } \\
\text { claro, o intérprete grava os } \\
\text { correspondentes das falas em } \\
\text { Libras. }\end{array}$ & $\begin{array}{l}\text { - [...] Mas se uma força for exercida } \\
\text { sobre o corpo, ele pode parar. }\end{array}$ \\
\hline Cena 8 & Aspectos da cena & Animação 4 \\
\hline $\begin{array}{lll}\text { Animação: } & \\
\text { apresentação } & \text { de } & \text { um } \\
\text { corpo } & & \text { em } \\
\text { movimento } & \\
\text { cessando } & \text { seu } \\
\text { movimento. } & \end{array}$ & $\begin{array}{l}\text { Em uma estrada, um skate com } \\
\text { um cachorro em cima } \\
\text { permanece em movimento. Até } \\
\text { que uma pessoa para o skate } \\
\text { com os pés. }\end{array}$ & $\begin{array}{l}\text { Mostra que quando uma força } \\
\text { resultante é aplicada contrária ao } \\
\text { movimento de um corpo, este pode } \\
\text { parar. }\end{array}$ \\
\hline Cena 9 & Aspectos da cena & Fala /Narração /Legenda \\
\hline $\begin{array}{lll}\text { Aplicação } & & \text { da } \\
\text { primeira } & \text { lei } & \text { de } \\
\text { Newton. } & & \end{array}$ & $\begin{array}{l}\text { Usando roupa preta em um } \\
\text { estúdio improvisado, de fundo } \\
\text { claro, o intérprete grava os } \\
\text { correspondentes das falas em } \\
\text { Libras. }\end{array}$ & $\begin{array}{l}\text { - A primeira lei de Newton explica a } \\
\text { necessidade do uso do cinto de } \\
\text { segurança. }\end{array}$ \\
\hline
\end{tabular}

\begin{tabular}{|l|l|l|}
\hline Cena 10 & Aspectos da cena & Animação 5 \\
\hline Animacão: & Em uma estrada um carro & Mostra que um corpo em movimento \\
\hline
\end{tabular}




\begin{tabular}{|c|c|c|}
\hline $\begin{array}{l}\text { apresentação de um } \\
\text { acidente de carro. }\end{array}$ & $\begin{array}{l}\text { conversível encontra-se em } \\
\text { movimento. O motorista do } \\
\text { carro não usa cinto de } \\
\text { segurança. O carro bate em uma } \\
\text { pedra enorme e o motorista é } \\
\text { arremessado para fora do carro. }\end{array}$ & $\begin{array}{l}\text { tende a permanecer em movimento, } \\
\text { se nenhuma força resultante atuar } \\
\text { sobre ele. }\end{array}$ \\
\hline Cena 11 & Aspectos da cena & Fala /Narração /Legenda \\
\hline $\begin{array}{lll}\text { Aplicação } & & \text { da } \\
\text { primeira } & \text { lei } & \text { de } \\
\text { Newton. } & & \end{array}$ & $\begin{array}{l}\text { Usando roupa preta em um } \\
\text { estúdio improvisado, de fundo } \\
\text { claro, o intérprete grava os } \\
\text { correspondentes das falas em } \\
\text { Libras. }\end{array}$ & $\begin{array}{l}\text { - Pois, a pessoa está em movimento } \\
\text { junto com o carro. Quando o carro } \\
\text { para, a pessoa continua em } \\
\text { movimento. }\end{array}$ \\
\hline Cena 12 & Aspectos da cena & Animação 6 \\
\hline $\begin{array}{l}\text { Animação: } \\
\text { apresentação de um } \\
\text { acidente de carro. }\end{array}$ & $\begin{array}{l}\text { Em uma estrada um carro } \\
\text { conversível encontra-se em } \\
\text { movimento. O motorista do } \\
\text { carro usa o cinto de segurança. } \\
\text { O carro bate em uma pedra } \\
\text { enorme e o motorista fica preso } \\
\text { ao carro pelo cinto de } \\
\text { segurança. }\end{array}$ & $\begin{array}{l}\text { Mostra que se uma força resultante } \\
\text { atuar sobre o corpo em movimento, } \\
\text { este pode cessar seu movimento, } \\
\text { ficando em repouso. }\end{array}$ \\
\hline Cena 13 & Aspectos da cena & Fala /Narração /Legenda \\
\hline \begin{tabular}{|lrr} 
Reforçando & a \\
aplicação & & da \\
primeira & lei & de \\
Newton. & & \\
\end{tabular} & $\begin{array}{l}\text { Usando roupa preta em um } \\
\text { estúdio improvisado, de fundo } \\
\text { claro, o intérprete grava os } \\
\text { correspondentes das falas em } \\
\text { Libras. }\end{array}$ & $\begin{array}{l}\text { - Por isso, use sempre o cinto de } \\
\text { segurança. }\end{array}$ \\
\hline
\end{tabular}

Fonte: Elaboração própria.

As gravações foram feitas com uma filmadora digital, em um cenário adaptado. Os sinais em Libras que representam termos físicos foram retirados do livro: "Sinalizando a Física”, volume 1: mecânica (CARDOSO; BOTAN; FERREIRA, 2010).

As animações, que buscavam apresentar o conceito na prática, foram desenvolvidas utilizando o software Adobe Flash (ADOBE, 2009).

A edição final do vídeo, que incluiu além da inserção e ajustes das animações e filmagens, a inserção de narrações em língua portuguesa e a legenda, foi realizada com o uso do software Power Producer (CYBERLINK CORP, 2009).

Nas figuras 1, 2, 3 e 4 a seguir são apresentadas imagens capturadas do vídeo desenvolvido. 


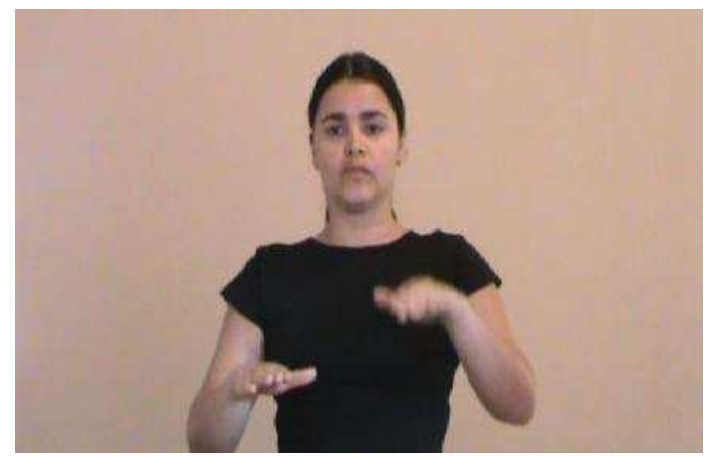

Fonte: Elaboração própria.

Figura 2: Animação 3

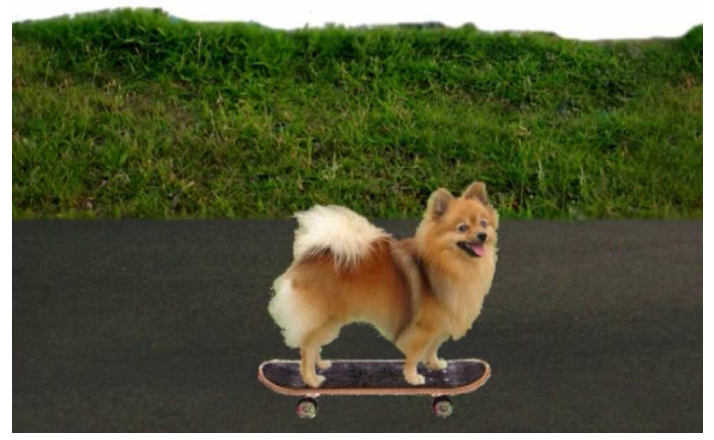

Fonte: Elaboração própria.

Figura 3: Animação 4

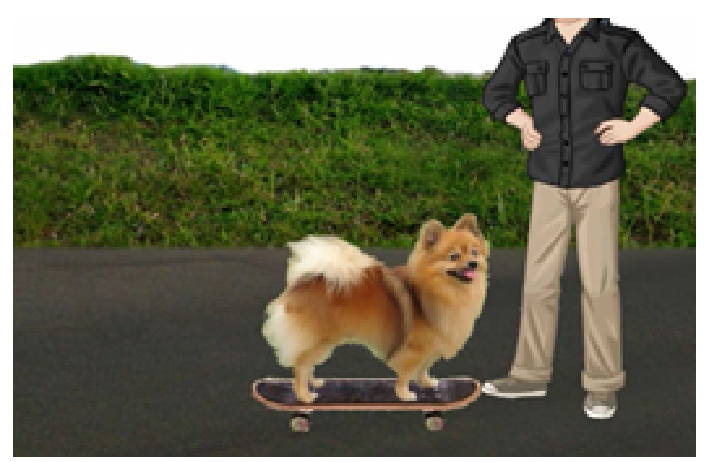

Fonte: Elaboração própria.

Figura 4: Animação 6 


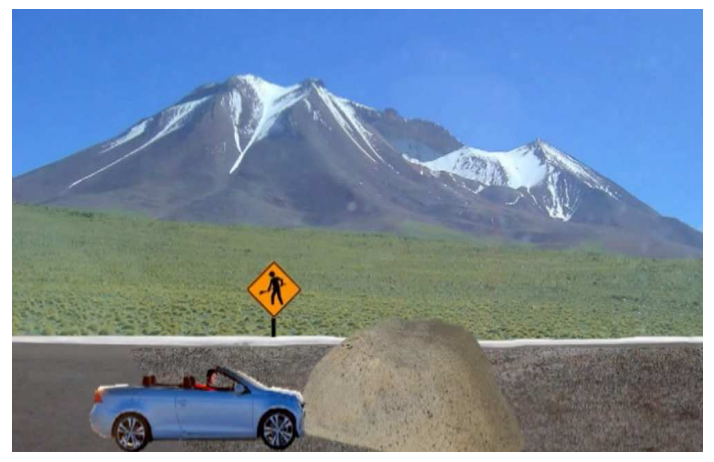

Fonte: Elaboração própria.

Foi desenvolvida uma sequência didática para o uso do vídeo bilíngue em um contexto inclusivo. Nesta sequência era previsto para o início da aula a apresentação de uma situação problema, e um tempo para que os alunos discutissem e buscassem uma explicação ou resolução para a situação problema. Em um terceiro momento, o vídeo bilíngue desenvolvido era apresentado ao aluno. Por fim, em um último momento era prevista uma segunda discussão acerca do conceito discutido. É apresentado na figura 5 um esquema da sequência de aula.

\section{Figura 5: Sequência da aula}

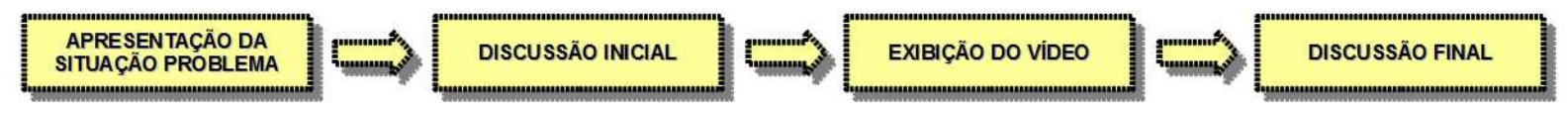

Fonte: Elaboração própria.

As situações problemas desenvolvidas visavam introduzir o conceito que seria discutido.

Situações problemas:

Situação 1: "Um skatista é lançado para frente quando seu skate para repentinamente ao se chocar com uma pedra. Porque o skatista não parou assim como ocorreu com o skate?" Juntamente com a situação problema foi apresentada a figura 6.

Figura 6: Representação da primeira situação problema sobre o conceito de Primeira Lei de Newton. 


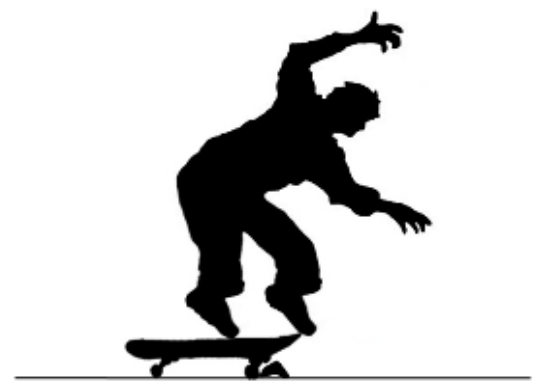

Fonte: Arquivo pessoal.

Situação 2: “Objetos colocados sobre uma mesa permanecem no mesmo local quando a toalha da mesa é removida rapidamente. Porque isso acontece?"

Juntamente com a situação problema foi apresentada a figura 7.

Figura 7: Representação da segunda situação problema sobre o conceito de primeira lei de Newton.

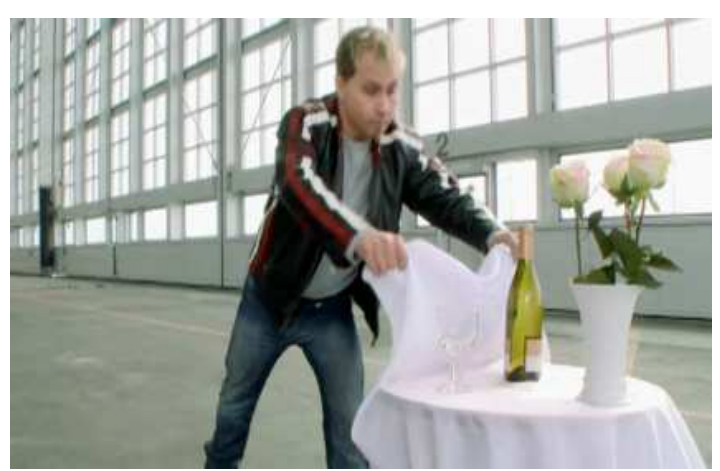

Fonte: Imagem Capturada do vídeo “BMW S1000 RR. Dinner for RR” (BMW.TV, 2010).

Resultado pretendido: Aqui é esperado que os alunos entendam que um corpo tende a permanecer em seu estado inicial, parado ou em movimento, a não ser que uma força seja aplicada diretamente sobre o corpo. Nos dois casos, as forças não são aplicadas diretamente sobre os corpos, o que não permite a alteração do estado inicial destes. Como as velocidades envolvidas (do skate e da toalha) não foram pequenas, podemos desconsiderar a ação da força atrito. Para velocidades menores, a força aplicada, ainda que indireta, seria suficiente para mudar o estado inicial dos corpos.

Além do plano de aula com uso de um vídeo bilíngue e situações problemas para introduzir as discussões em sala de aula foi desenvolvido um questionário com três questões problemas para serem usadas antes e depois da aula. O objetivo desse questionário primeiramente é observar as concepções prévias que os alunos têm da primeira lei de Newton, e o uso do mesmo questionário após a aula tem como objetivo analisar se o plano 
desenvolvido foi eficiente em ensinar o conceito de primeira lei de Newton e se os alunos propuseram respostas mais adequadas para as questões problemas após a aula.

O questionário desenvolvido é apresentado no quadro 2.

\section{Quadro 2: Questionário}

1-O motorista freia bruscamente até parar o ônibus. As pessoas que estão dentro do ônibus são jogadas para frente. $\mathrm{O}$ que se pode dizer sobre essa situação considerando as leis de Newton?

a) ( ) Para toda ação existe uma reação e se o ônibus freou algo teria que acontecer, como as pessoas sendo jogadas para frente do ônibus, a roda do ônibus se soltar, ou mesmo, o ônibus continuar em movimento com velocidade constante.

b) ( ) Esta situação não é explicada pelas leis de Newton.

c) (x) As pessoas dentro do ônibus estão em movimento junto com o ônibus. Quando o ônibus freia as pessoas continuam em movimento por inércia.

d) ( ) Somente as pessoas com massas pequenas que teriam uma tendência de serem jogadas para frente do ônibus.

2- Um carro em alta velocidade freia bruscamente. O motorista está usando cinto de segurança, mas o carona (sentado ao lado do motorista), não está usando. Sobre o motorista e o carona, considerando as leis de Newton, seria correto afirmar que:

a) (x) Há uma possibilidade bem maior do carona ser lançado para fora do carro em relação ao motorista que está usando o cinto. Ambos tenderiam por inércia a manter seu movimento, mas o cinto de segurança atuaria contrário a este movimento.

b) ( ) O motorista e o carona estarão em segurança, pois como estão em movimento junto com o carro, irão parar também junto com o carro.

c) ( ) As leis de Newton não abrangem situações como estas. Se tanto o motorista como o carona não estivessem usando o cinto de segurança, poderia ser utilizado o princípio da inércia, pois, neste caso os dois tenderiam a continuar em movimento.

d) ( ) Mesmo que não use o cinto de segurança, somente se o carona possuir uma massa pequena é que terá a tendência de continuar em movimento, correndo o risco de ser lançado para fora do carro.

3-Um cronômetro é disparado. Quando este marca 5 segundos, um carro que até então estava parado, entra em movimento. Sua velocidade começa a aumentar até o cronômetro marcar 10 segundos. Após os 10 segundos o carro continua em movimento com uma velocidade constante.

Em que intervalos de tempo o corpo se encontra em Inércia?

a) ( ) Somente no intervalo de tempo entre 0 e 5 segundos .

b) ( ) Somente no intervalo de tempo entre 5 e 10 segundos.

c) ( ) Somente no intervalo de tempo após 10 segundos.

d) (x) Somente nos intervalos de tempo entre 0 e 5 segundos e após os 10 segundos.

Fonte: Elaboração própria.

\section{Análise do uso do plano de aula em uma turma inclusiva}


O plano de aula apresentado neste trabalho foi utilizado como estratégia de ensino em uma turma de segundo ano do ensino médio. Participaram da aula dezoito alunos, uma das alunas da turma tinha uma perda auditiva severa.

Como anteriormente descrito a aula começou pela discussão da situação problema. Em seguida foi apresentado o vídeo desenvolvido, e logo após foi retomada as discussões. Antes e após a aula foi solicitado aos alunos que respondessem ao pequeno questionário apresentado anteriormente.

Foi possível perceber que os alunos participaram da aula, a ideia de trabalhar com uma situação problema para introduzir a aula se mostrou muito positiva. A segunda situação problema chamou muito a atenção dos alunos, em um primeiro momento eles acreditavam que era impossível puxar uma toalha e deixar os objetos sobre a mesa.

O vídeo também prendeu a atenção dos alunos, a ideia de usar um cachorro em cima de um skate foi muito bem aceita. As discussões desenvolvidas depois do uso do vídeo mostraram que os alunos conseguiram propor soluções melhores para as situações problemas. Pode-se perceber que todos os alunos participaram da aula e aparentemente compreenderam o conceito. A análise da resolução do questionário mostrou que os alunos apresentaram soluções mais adequadas para as situações problemas depois da aula apresentada. Cabe destacar, que o questionário respondido antes da aula mostrou que os alunos tinham concepções prévias corretas sobre a primeira lei de Newton, contudo, após a aula observou-se que essas concepções se tornaram ainda melhores. Após a aula pode-se perceber que os alunos apresentaram um rendimento superior no questionário de ao menos $25 \%$.

O rendimento da aluna incluída na resolução do questionário foi ainda maior, a aluna apresentou um rendimento de $100 \%$ a mais no segundo questionário (questionário respondido após a aula) quando comparado ao primeiro (questionário respondido antes da aula).

\section{Considerações Finais}

O plano de trabalho desenvolvido se mostrou adequado para ser utilizado em uma turma inclusiva de ensino de Física.

$\mathrm{O}$ uso das situações problemas para introduzir o conceito de primeira lei de Newton mostrou-se muito eficiente, os alunos participaram da aula e, mostraram ter compreendido o conceito juntos, assim como é esperado em uma proposta de ensino inclusiva. 
Foi possível perceber que alunos com e sem surdez aprenderam o conceito, e que a proposta aqui apresentada pode ser uma estratégia muito positiva em uma turma inclusiva de Física.

Acredita-se que a proposta aqui apresentada para o conceito de primeira lei de Newton pode ser utilizada para ensinar outros conceitos da Física, e pode ser considerada uma proposta inclusiva.

\section{PHYSICAL EDUCATION AND INCLUSIVE EDUCATION: TEACHING THE FIRST LAW OF NEWTON}

ABSTRACT: This paper presents a discussion on the inclusion of deaf students in physics class. The article discusses how to build a lesson plan for teaching Newton's first law in an inclusive education. Using a bilingual proposal is developed a teaching plan that has a video bilingual, problem situations for introduce the discussions, and a closed questionnaire to assess learning. Participated eighteen students from the second year of high school to a public school in the state of São Paulo. The results show that was developed an inclusive proposal, since this could provide the possibility of learning to students with and without hearing loss, to meet the learning styles and rhythms was created a proposal that could teach all students the same concept at the same time.

KEYWORDS: Inclusive education. Physics teaching. Deafness. Bilingual education.

\section{REFERÊNCIAS}

ADOBE. Flash, Adobe Systems Incorporated. 2009. Disponível em:

<http://www.adobe.com/br/products/flashplayer/>. Acesso em: 03 jan. 2009.

BMW.TV. BMW S1000 RR. Dinner for RR. 2010. Disponível em:

<http://bmw.tv/com/home/showVideo.do?articleID=7005\&spaceID=2>. Acesso em: 12 fev. 2011.

BRASIL. Constituição (1988). Constituição da República Federativa do Brasil, de 05 de outubro de 1988. Brasília, 1988. Disponível em:

<http://www.senado.gov.br/legislacao/const/con1988/CON1988_05.10.1988/CON1988.sht>. Acesso em: 01 jan. 2011.

Convenção interamericana para a eliminação de todas as formas de discriminação contra as pessoas portadoras de deficiência. Convenção da Guatemala, de 28 de maio de 1999, ratificada pelo Decreto no 3.956, de 8/10/2001. Brasília, 2001. Disponível em: <http://www.ampid.org.br/Docs_PD/Convencoes_ONU_PD.php\#guatemala>. Acesso em: 01 abr. 2011.

Decreto-lei $\mathrm{n}^{\circ} 186$ de 2008. Convenção sobre os direitos das pessoas com deficiência, ratificados pelo Congresso Nacional pelo decreto legislativo $n^{\circ} \mathbf{1 8 6} / \mathbf{2 0 0 8}$ de 10/07/2008. Brasília, 2008. Disponível em: <http://www2.senado.gov.br/bdsf/item/id/99423>. Acesso em: 01 abr. 2011. 
Decreto-lei n ${ }^{\circ}$ 9.394, de 20 de Dezembro de 1996. Estabele as diretrizes e bases da educação nacional. Brasília, 1996. Disponível em:

<http://www.planalto.gov.br/ccivil_03/Leis/L9394.htm>. Acesso em: 07 abr. 2013.

Lei $\mathrm{n}^{\circ} 10.436$ de 24 de abril de 2002. Dispõe sobre a língua brasileira de sinais. Brasília, 2002. Disponível em: <www.libras.org.br>. Acesso em: 10 fev. 2010.

Ministério da Educação. Política nacional de educação especial na perspectiva da educação inclusiva. Brasília: SEESP/MEC, 2007.

CARDOSO, F. C.; BOTAN, E.; FERREIRA, M. R. Sinalizando a física: 1 - Vocabulário de Mecância. 1. ed. Sinop: Projeto "Sinalizando a Física", 2010. Disponível em:

<http://sinaisdafisica.site50.net/index.php?p=vocmec>. Acesso em: 05 set. 2010.

CYBERLINK CORP. Power producer. Santa Clara, 2009. Disponível em:

<http://www.cyberlink.com/multi/products/main_3_en_US.html>. Acesso em: 04 jan. 2009.

MENDES, E. A radicalização do debate sobre inclusão escolar no Brasil. Revista Brasileira de Educação, Rio de Janeiro, n.33, p.387-559, 2006.

PERLIN, G.; STROBEL, K. Fundamentos da educação de surdos. Florianópolis: UFSC, 2006.

RODRIGUES, D. Dez ideias (mal) feitas sobre a educação inclusiva. In: RODRIGUES, D. (Org.). Inclusão e educação: doze olhares sobre a educação inclusiva. São Paulo: Summus Editorial, 2006. p.302-303.

SACKS, O. W. Vendo vozes: uma viagem ao mundo dos surdos. São Paulo: Companhia das Letras, 1998.

UNESCO. Conferência Mundial sobre Educação para Todos Satisfação das Necessidades Básicas de Aprendizagem. Declaração mundial sobre educação para todos, plano de ação para satisfazer as necessidades básicas de aprendizagem. Jomtien, 1990. Disponível em: <http://www.dominiopublico.gov.br/download/texto/ue000108.pdf>. Acesso em: 01 abr. 2011.

UNESCO. Declaração de Salamanca. Sobre princípios, políticas e práticas na área das necessidades educativas especiais. Salamanca, 1994. Disponível em:

<http://portal.mec.gov.br/seesp/arquivos/pdf/salamanca.pdf>. Acesso em: 20 out. 2009. 